\title{
Discrete fracture network modelling for hard rock slopes
}

\author{
FM Weir Pells Sullivan Meynink, Australia \\ MJ Fowler Pells Sullivan Meynink, Australia
}

\begin{abstract}
The design of excavations in rock must, implicitly or explicitly, consider the influence of small and large scale geological structures. For most hard rock sites, the complexity of a fractured rock mass is best captured using a three-dimensional fracture system model based on field data. A discrete fracture network (DFN) approach involves stochastic modelling of the smaller scale, non-deterministic structures. For slope stability projects DFN modelling provides a valuable geotechnical tool for visualisation of a rock mass, identification of likely failure mechanisms and a method for considering uncertainty both in terms of natural stochastic variability and sampling.
\end{abstract}

This paper presents a suite of DFN modelling undertaken for the design of a large open pit in Australia. The model inputs and development are briefly presented, along with the various applications of the DFN modelling. A key advantage of the DFN approach for design studies is its probabilistic application to analyses and results. Multiple realisations of the same model were generated for four structural domains, with the stability analysis carried out on each iteration. The proportion of unstable slope for a range of conditions is compared with results from traditional kinematic and statistical analyses.

\section{Introduction}

The identification, analysis and design of hard rock slopes susceptible to wedge failure is applicable to both civil and mining engineering. Traditional statistical analyses of geological structures, while considered industry standard practice, have inherent limitations. These analyses attempt to indicate the spatial distribution and orientation of defects with the results interpreted using experience and empirical rules. An example is the assumption of ubiquitous discontinuities of infinite length intersecting the excavation. Whilst this simplifies the kinematic analysis, it results in a rather unrealistic conceptual fracture network (Figure 1).

a)

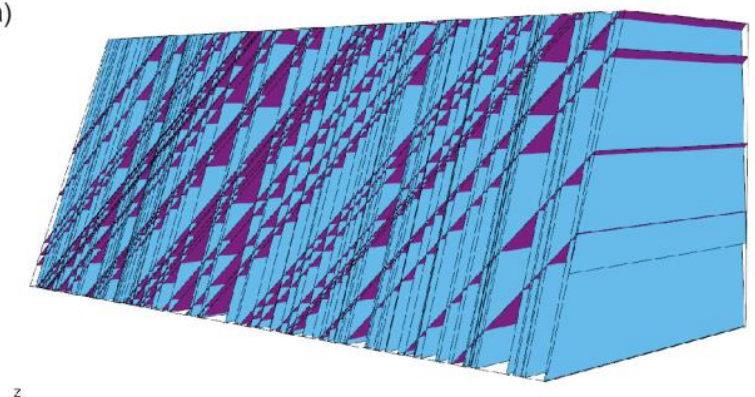

b)

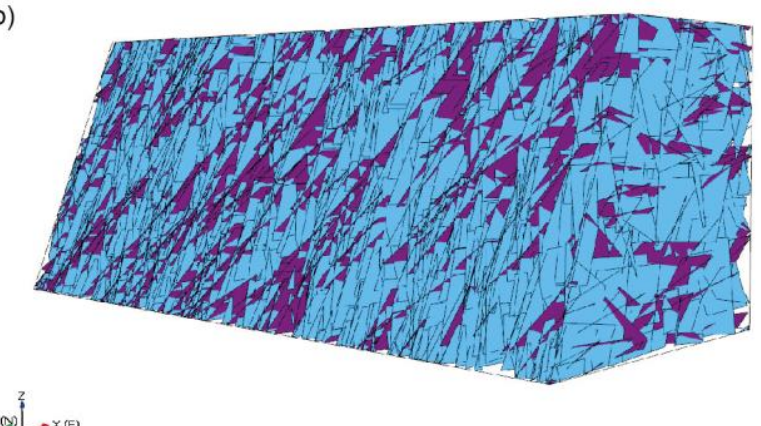

Figure 1 A comparison of fracture network models based on assumptions of: (a) ubiquitous infinite fractures of constant orientation; and (b) distributable, length variable and dispersed fracture orientations (after Rogers et al. 2006; Weir \& Fowler 2014)

The analysis of geological structures for rock slopes, irrespective of the method, relies on three basic premises:

1. The characteristics of the geological structures (e.g. type, orientation, intensity, position in space, infill type and hardness) can be determined. 
2. The fracture population description can be appropriately assessed from sampling techniques such as boreholes and scan line mapping.

3. Structural domains can be defined, with the fracture population within the region having similar characteristics.

Fracture network analysis relies on an additional fourth premise:

4. A reliable model of the geological structures in the rock mass can be produced. This implies that a statistical sampling of any property will give a representative picture of the entire portion of the rock mass (Grenon \& Hadjigeorgiou 2008).

Coates (1981) was an early advocate for the use of probabilistic techniques in rock slope stability as a way to account for the inherent variability of input data. Stochastic analyses are probabilistic simulations based on a set of input parameters and modelled functions to describe the distributions of the data. Every time a stochastic model is generated, a different result is expected. It is necessary to do sufficient modelling to understand the distribution of outcomes. However, determining what is sufficient and dealing with the distribution of results requires careful consideration.

With recent improvements to field data collection (e.g. borehole televiewer data) and computational power, the discrete fracture network (DFN) approach has become recognised internationally as a valuable tool for modelling some geomechanical problems encountered when designing excavations in fractured rock masses.

Stochastic models provide a powerful tool for representing fracture systems based on available structural data. DFN models are those that represent a rock mass as an assembly of discontinuities. The DFN technique utilises the field measurements (from boreholes or scanlines) in stochastic analyses to generate a range of possible models. While initially used to simulate fluid flow around nuclear waste sites, in recent years there has been an increased focus on DFN modelling of fracture hydrocarbon reservoirs with some limited use in advanced civil and mining rock engineering studies (e.g. Starzec \& Andersson 2002; Rogers et al. 2006; Gasc-Barbier et al. 2008; Grenon \& Hadjigeorgiou. 2008).

The choice of input variables to generate a DFN depends on the complexity of the geological model of the site, the scale and purpose of the modelling. The development of a fracture network for slope stability applications requires a minimum of four inputs: orientation, intensity, spatial distribution and size. While the first three parameters are readily obtained from borehole data, the fourth (size) is more difficult to determine.

This paper presents a case study of DFN modelling to assist with the design of a proposed open pit mine in Australia. Fracture network modelling was undertaken as part of the slope design process, considering the likely structural control on slope stability, and because of the significant investment a large open pit represents. Recent years have seen the development of multiple fracture system generators of varying complexity and ease of use. The majority of these generators are research based and have not been adequately verified for engineering applications. The modelling presented here has been undertaken using the DFN code FracMan ${ }^{\circledR}$ as it is commercially available software that has integrated a number of fracture system models and has been utilised for a variety of engineering applications (Dershowitz et al. 2011).

\section{Case study site}

The DFN modelling reported here was undertaken to assist with the geotechnical slope design of a large open pit in Australia. An extensive underground operation currently mines the northern portion of the orebody, with open cut operations proposed to commence in the southern portion of the orebody (Figure 2). The proposed starter pit is about $1,600 \mathrm{~m}$ wide and $550 \mathrm{~m}$ deep, with mining progressing through a series of pushbacks. 


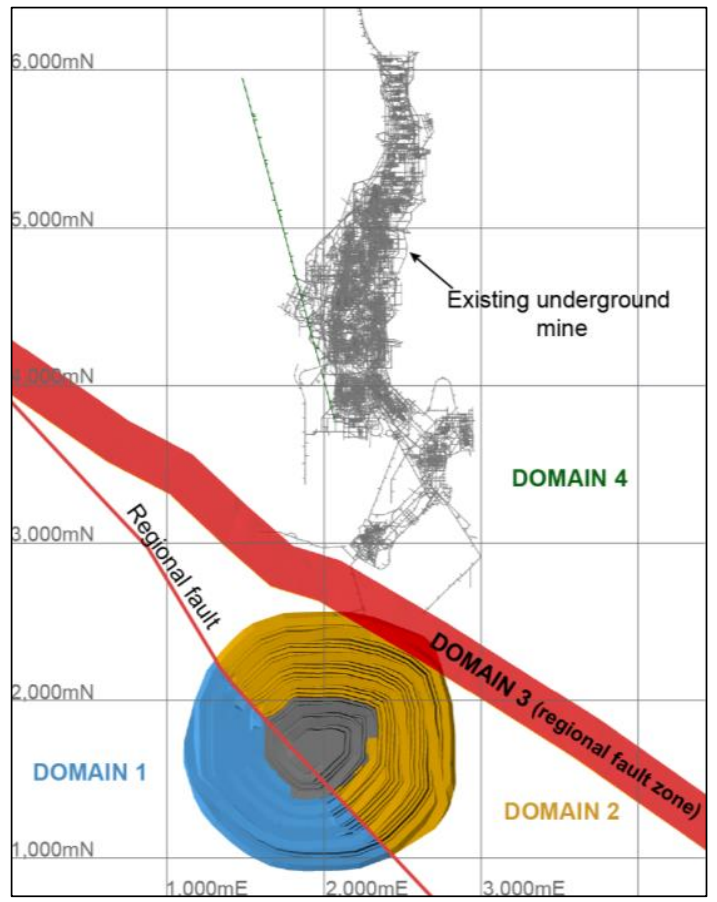

Figure 2 Plan showing the proposed starter pit, structural domains, regional scale faults and existing underground mine. The pit is grey in crystalline basement and coloured for sedimentary

Data in the southern mine area is constrained to borehole data. A comprehensive campaign of acoustic borehole imaging and quality control at the site allowed the development of a large, high quality structural database from some 500 boreholes.

The orebody at the site is contained in a breccia complex hosted by granite. These rocks are very high strength with a typical unconfined compressive strength of 100 to $230 \mathrm{MPa}$. Horizontally bedded sedimentary rocks overlie the crystalline basement and range between 300 to $350 \mathrm{~m}$ thick across the site.

An array of irregular and discontinuous brittle faults, with multiple and episodic movement histories crosscut the deposit. In particular, two regional scale faults transect the site and serve as a framework for the four broad structural domains at the site (Figure 2). These regional faults are interpreted as old structures that have undergone multiple stages of reactivation.

The existing underground mine is located in structural Domain 4 (Figure 2). Mapped faults for the existing mine have been correlated using three-dimensional modelling software to produce about 680 triangulations of interpreted fault planes. Figure 3 shows an orthogonal view of the three-dimensional fault model, which was used to estimate fracture size distribution. It also served as a comparative measure of intensity.

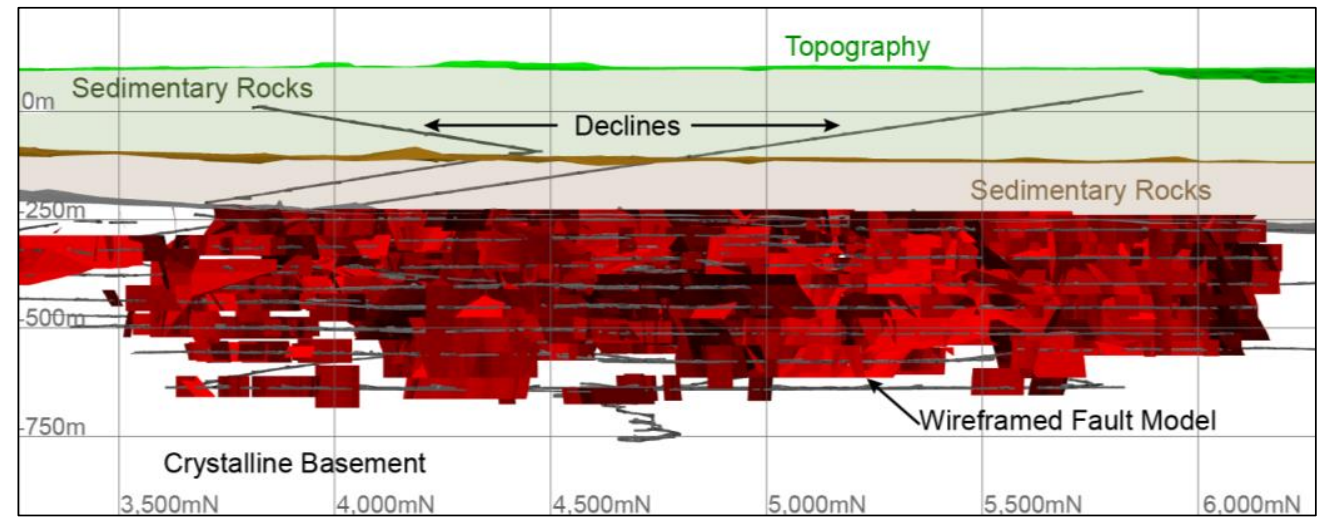

Figure 3 A north-south section through the three-dimensional fault wireframe model in the northern mine area 
Advanced analytical techniques were applied due to both the size of the pit and the aggressive slope design adopted. A fracture network approach was one of these techniques and was appropriate considering that slope stability is expected to be structurally controlled.

\section{$3 \quad$ Model inputs}

\subsection{Introduction}

DFNs were developed using the geotechnical drilling data for each of the four structural regions (Figure 2). While the overall database of some 500 boreholes was used to educate the engineering model for the site, a subset of 24 geotechnical boreholes were selected for use in the DFN modelling. It is assumed that the fracture parameters evaluated from these boreholes is representative of the rock volume for the structural domain within which they are situated. The boreholes were selected as they have a complete data record (including fracture orientation, spacing, aperture and lithology) of high quality.

The generation of a DFN for geotechnical purposes requires four primary inputs: orientation, intensity, spatial distribution and size. For this study the first three properties were determined from the borehole data in each region. The fault wireframe model from the existing underground mine educated structure size. While fracture intensity is based on borehole sampling it was also compared to the fault wireframe model. The method employed to derive appropriate input parameters is summarised in Figure 4 and discussed in the following sections.

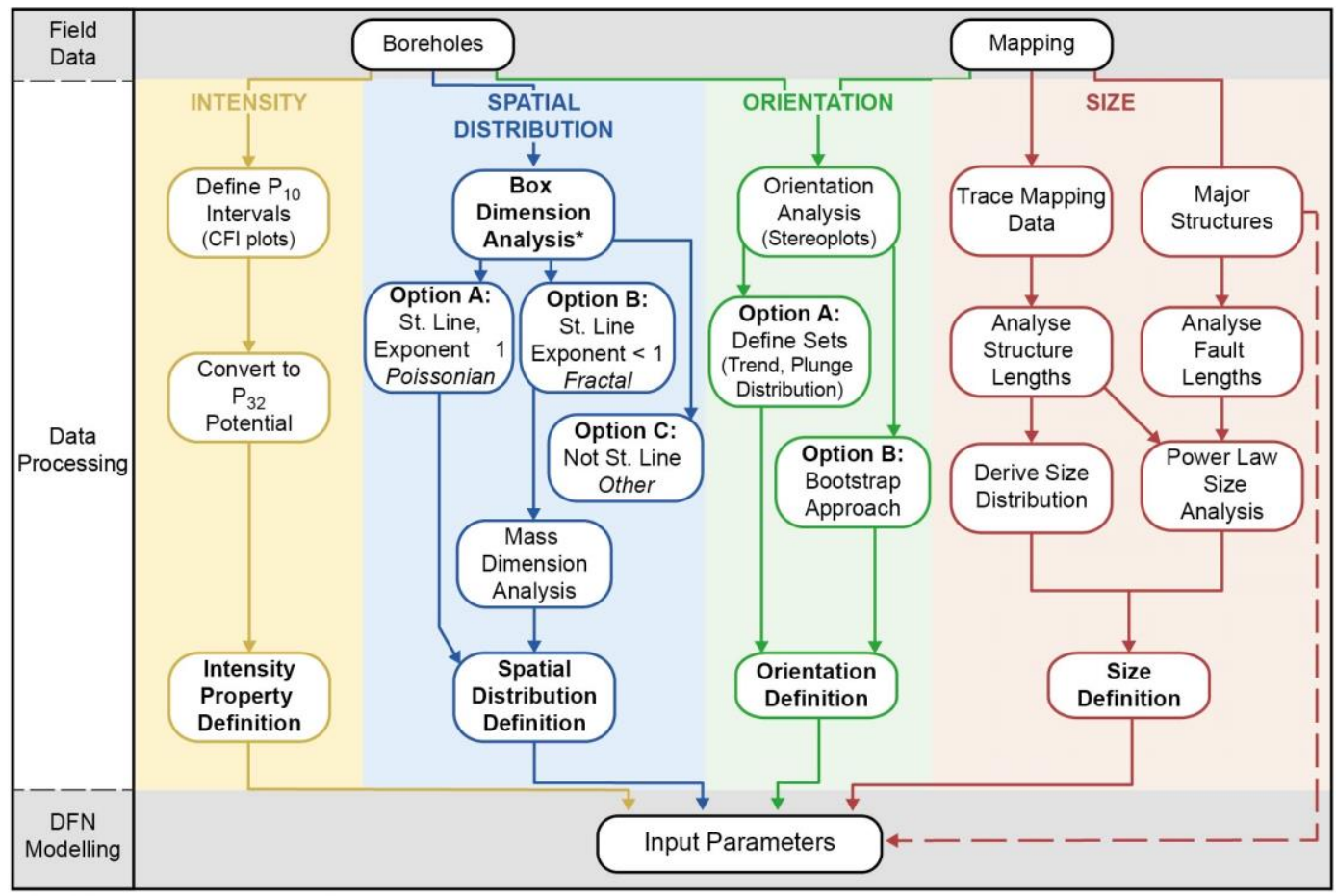

Note: * Should be conducted on defined sets individually

Figure 4 A summary of the major workflow steps for statistical data processing to derive the necessary input parameters (from Weir \& Fowler 2014)

\subsection{Type}

The selection of appropriate geological structures to form the basis of the stochastic fracture network for each domain was largely dependent on their likelihood to serve as sliding planes for potentially large unstable rock blocks. The appropriate selection of defect types for DFN modelling was important not only from an engineering application perspective, but also because the generation of a stochastic fracture model representing all the types of discontinuities detected in all the boreholes would make excessive demands upon both computer power and time. 
For this study fracture networks were built for each of the four structural domains at the site and are representative of a single defect type. The fracture networks for Domains 2 to 4 are representative of faults and shears. Domain 1 was constructed as a joint network as there are few faults and shears.

\subsection{Orientation}

When the number of observed fractures is large and they exhibit clustering on a stereograph, the separation of fractures into orientation sets can improve the reliability of a DFN model (Starzec \& Andersson 2002; Dershowitz et al. 2011). Priest (1993) discusses the basic principles for set identification and delineation.

For each domain and selected structure type, a visual assessment of sets on a stereograph was undertaken, concentrating upon the main clusters of structures. Application of the Terzaghi (1965) correction factor did not result in the identification any alternate fracture sets. A Fisher probability distribution function (pdf), equivalent to a normal distribution for oriented data on a sphere, was determined to be an appropriate fit. Each orientation set was characterised by its mean pole trend (azimuth) and plunge (inclination) vectors, a Fisher dispersion coefficient and the amount of fractures expressed as a percentage of the total number of fractures. The dispersion coefficient is a measure of the sample population scatter about the mean pole vector. Higher coefficient values imply less scatter.

\subsection{Intensity}

Volumetric fracture intensity is one of the most important fracture network characteristics. DFN theory uses a unique terminology of defect intensity (Mauldon \& Dershowitz 2000), which include:

- $P_{10}$ - a linear measure, i.e. the number of fractures per metre $(1 / \mathrm{m})$.

- $\mathrm{P}_{21}-$ an areal measure, i.e. the trace length per unit of mapped area $\left(\mathrm{m} / \mathrm{m}^{2}\right)$.

- $P_{32}-$ a volumetric measure, i.e. fracture surface area per unit volume of rock $\left(\mathrm{m}^{2} / \mathrm{m}^{3}\right)$.

While $P_{32}$ is an important parameter in DFN theory, it is theoretically derived and cannot be measured in situ. $P_{10}$ and $P_{21}$ are obtained from field measurements and used to constrain fracture intensity.

Cumulative fracture intensity plots of each borehole were utilised to identify zones where the average degree of fracturing remains constant over significant intervals (Figure 5). Fracture orientations in each zone of constant fracturing were also examined (Figure 5). Interpretation from a number of boreholes in each domain resulted in the definition of $\mathrm{P}_{10}$ intervals, which provided the basis for the DFN intensity.

Rogers (2006) found that, to construct a fracture network that best honours the relative spatial intensity and the actual intensity, the model should use $\mathrm{P}_{10}$ conditioning at the boreholes. This approach allows the spatial intensity property to control the probability of fracture occurrence in certain areas of a model, with modelling continuing until the average $\mathrm{P}_{10}$ from the conditioning boreholes has been met. In this study the boreholes were imported into the modelling software and used to control fracture intensity. 


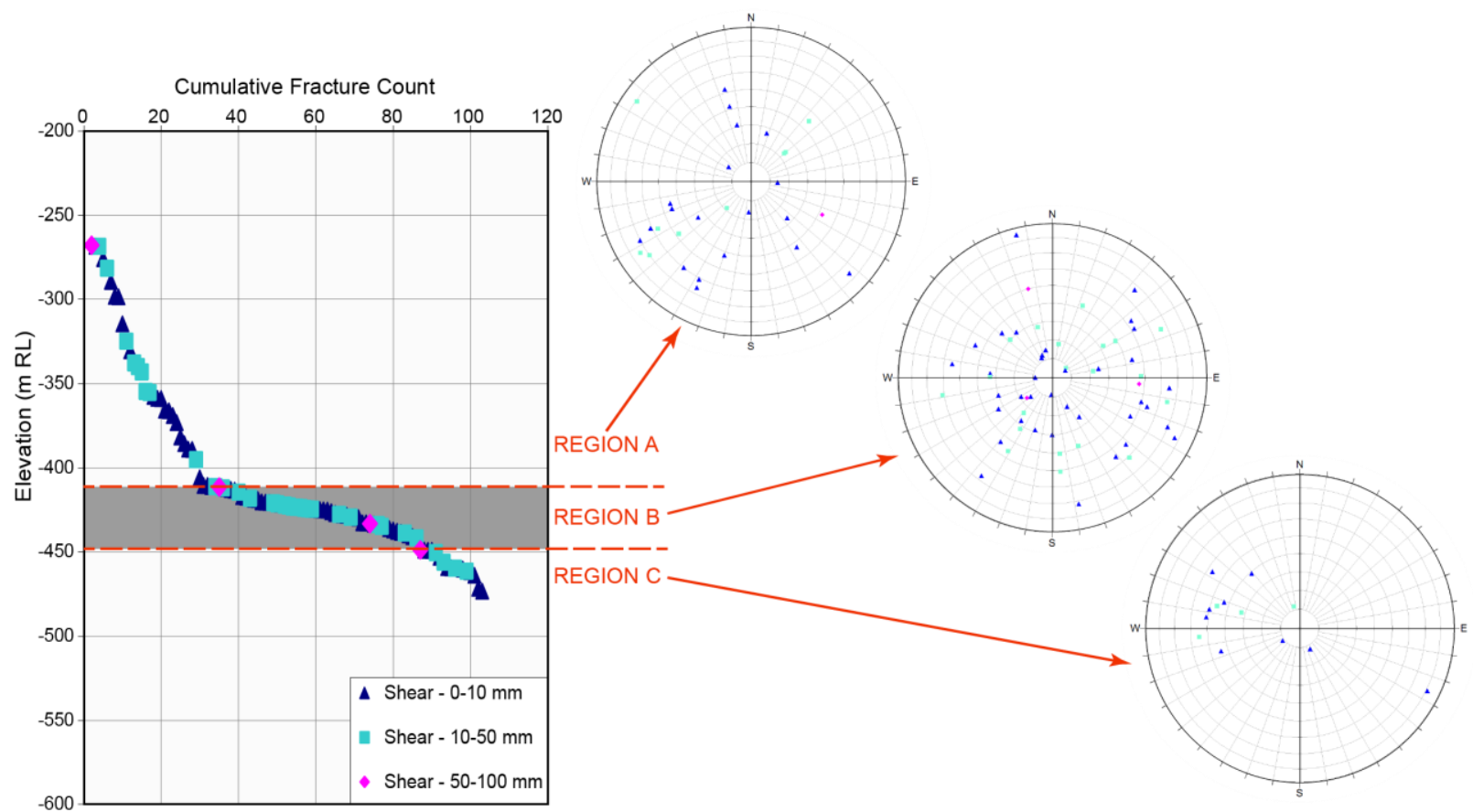

Figure 5 An example of a cumulative fracture intensity plot, from a borehole in Domain 2. All stereographs are lower hemisphere, equal area projections

\subsection{Spatial distribution}

Previous studies have shown that a number of fracture location models such as Levy-Lee (fractal) or Nearest-Neighbour (clustered) may best represent observed data (Barton \& La Pointe 1995; Geier \& Thomas 1996; Dershowitz et al. 2011). Priest (1993) suggests that in the absence of a strong clustering pattern, a random fracture location model, based on a Poisson process, be adopted.

The spatial distribution of fractures is estimated from spacing measurements along sampling lines such as boreholes or from two-dimensional rock face mapping. A box dimension analysis subdivides a borehole into segments of equal lengths and then determines the number of intervals that have fractures in them. The slope of the plot is then used to assess different possible spatial models (Figure 6(a)). If the result is a straight line with a slope that is less than one, then the spatial model is described by fractal clustering. If the slope of the line is approximately zero, the fractures in the borehole are located according to a Poisson process. If the result is not a straight line then the spatial pattern is neither fractal nor Poissonian (Dershowitz et al. 2011). For this study the box dimension analyses found that a Levy Lee (fractal) spatial distribution model was a best fit to the data.
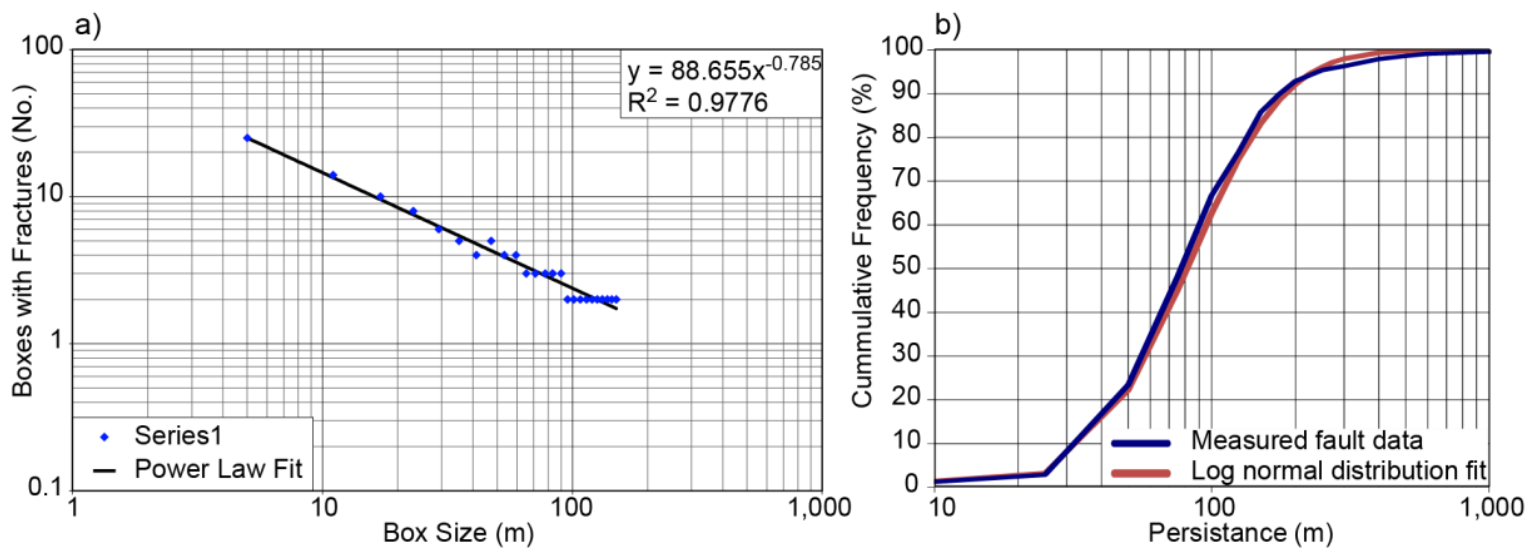

Figure 6 (a) An example of a spatial model assessment with a box dimension plot; and (b) persistence of wireframed faults from the existing underground mine in Domain 4 
If the results of the box dimension analysis indicate that the spatial model is described by fractal clustering, then a mass dimension analysis is undertaken to derive the fractal dimension $D$. The mass dimension analysis subdivides a borehole into segments of equal length with a circle placed at every fracture location down the borehole and the number of fractures within the circle calculated (Dershowitz et al. 2011). This exercise is repeated for various circle sizes. When the average number of fractures in a circle is plotted against the circle radius on a log-log scale it will form an approximately straight line. The fractal dimension $D$ derived from the equation for the line, which is expressed as $N(L)=\rho L D$, where $N(L)$ is the average number of fractures, $L$ is the interval length, $D$ is the mass (fractal) dimension and $\rho$ is a constant. For this study, a mass dimension analysis was undertaken to derive the fractal dimension; however, the fractal parameters from this analysis were such that the distribution model was effectively random.

\subsection{Size}

Fracture size is typically the most difficult parameter to quantify, particularly from borehole datasets. Some studies have relied upon published fracture lengths for the same rocks at different sites (Weir et al. 2014), while others have estimated size using empirical relationship between fracture length and aperture for similar rock types (e.g. Starzec \& Andersson 2002).

The fault wireframe model from the existing underground mine was used to educate the fault DFN models on structure size. Analysis of the data found a log normal distribution, with a mean of $80 \mathrm{~m}$ and standard deviation of $94 \mathrm{~m}$, to be the best fit (Figure 6(b)). Joint persistence is more difficult to quantify and a constant diameter of $100 \mathrm{~m}$ was adopted for Domain 1. Based on experience with similar rock types, this is considered an upper bound conservative estimate.

\section{$4 \quad$ Stochastic fracture network generation}

The generation region for the fracture network was a rectangular prism, with the dimensions varying between each region. The generation volume exceeded the volume actually required for slope stability simulations but was kept large to minimise edge effects. Figure 7 shows an example for Domain 1 with twelve boreholes of varying plunge and azimuth.

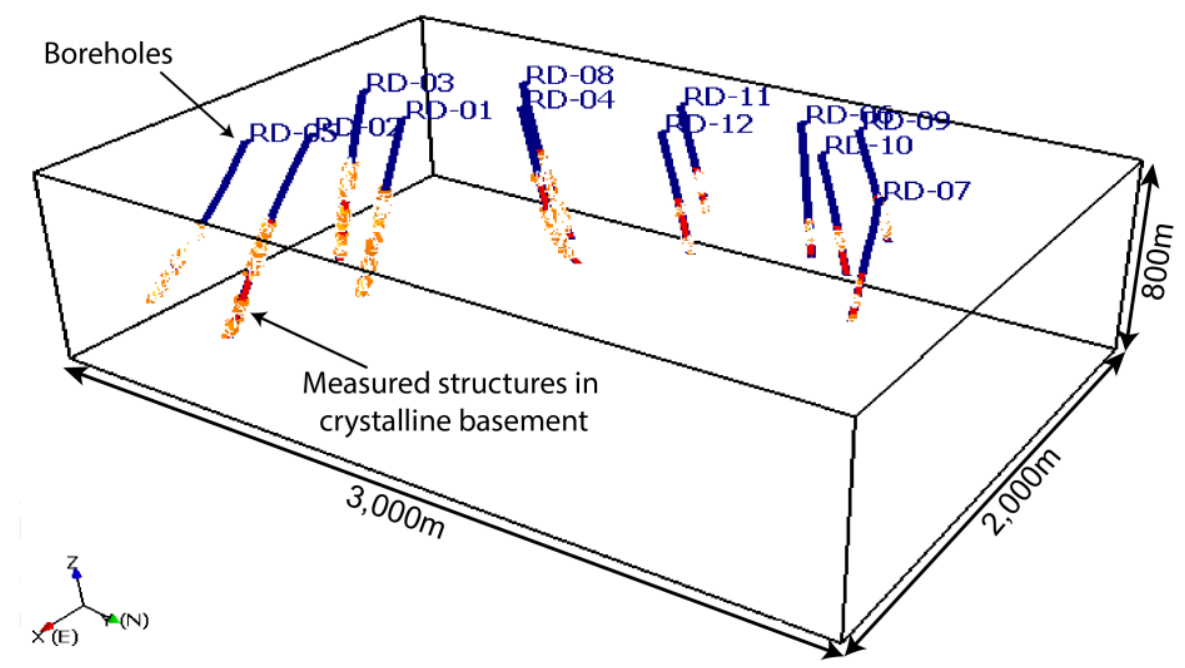

Figure 7 Domain 1 model generation region and boreholes used for input data. Input fractures are shown in orange and defined basement intervals red

Spatial variation in fracture properties directly controls the complexity of a DFN model. When a modelled area is structurally and/or lithologically heterogeneous, multi-domain DFN models may represent a rock volume (Starzec \& Andersson 2002). Multi-domain models demand substantial computer power for both the stochastic fracture generation process and subsequent stability analysis. To optimise processing times 
the four structural domains were modelled individually as geologically/structurally homogeneous areas with the statistical moments describing the fracture network variables spatially independent.

Fracture orientations were defined by distinct sets from the borehole data. Actual borehole intercepts were used to directly control fracture intensity, with the select boreholes and fracture intercepts imported into the program. Representative fracture sizes were generated from either a lognormal probability distribution with a mean of $80 \mathrm{~m}$ and a standard deviation of $100 \mathrm{~m}$ or as a constant size of $100 \mathrm{~m}$, depending on the structural domain. The generation region was then populated until the average $P_{10}$ across the boreholes was achieved. The generated fracture shapes were approximated with four-sided polygons.

DFN modelling is an iterative process, with refinement of input parameters until an acceptable agreement with field measurements is obtained. As the first step, five DFN models were generated and a validation process undertaken and inputs, such as orientation, refined before stochastic generation was undertaken.

\subsection{Model validation}

A fundamental question for DFN modelling is; are the generated fracture models representative of the field data (Grenon \& Hadjigeorgiou 2008)? This is difficult to verify as field data for most projects is limited. To address this issue the authors have adopted an approach where the generated fracture system is sampled by linear techniques (e.g. borehole). This means that the results of the sampled virtual rock are directly compared to the field data. Figure 8 shows a comparison of the measured orientation data from the boreholes and the sampled virtual rock.
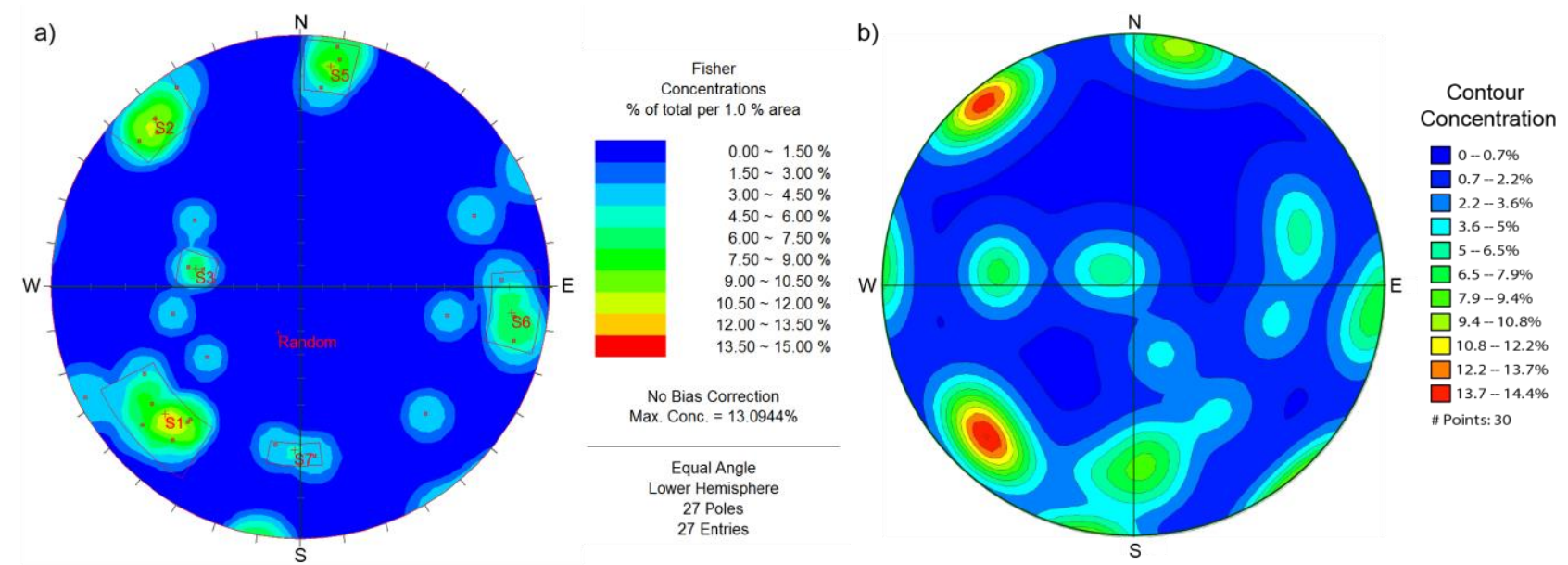

Figure 8 Stereographs showing: (a) poles to measured faults and shears; and, (b) contours of synthetic fractures intersected by boreholes. Both stereographs are lower hemisphere, equal area projections

A two-dimensional cross-section through a DFN is an important method for assessing the appropriateness of the model. The visual evaluation is a way of checking that the network makes sense from a geological perspective and that variables, such as length and intensity, are as expected based on input values.

For comparative purposes, a $\mathrm{P}_{32}$ for the existing underground wireframe model was calculated. For this $\mathrm{P}_{32}$ estimate, a volume was constructed tightly around the fault wireframes in the three-dimensional modelling software Vulcan ${ }^{\mathrm{TM}}$. The program then reported fracture surface area and volume separately, with $\mathrm{P}_{32}$ then manually calculated, with a resulting value of $0.06 \mathrm{~m}^{2} / \mathrm{m}^{3}$. The range and mean of simulated $P_{32}$ for each Domain is summarised in Table 1. The mean simulated $P_{32}$ for Domain $4\left(0.07 \mathrm{~m}^{2} / \mathrm{m}^{3}\right)$ is a good match to that calculated from the fault model $\left(0.06 \mathrm{~m}^{2} / \mathrm{m}^{3}\right)$, which is also in the northern mine area. The simulated $\mathrm{P}_{32}$ for Domains 2 and 3 are higher than that of the fault model. In particular, Domain 3 is significantly higher, which is considered appropriate for a highly faulted zone. 
Table 1 Summary of simulated $\mathrm{P}_{32}$ values

\begin{tabular}{cc|cccc}
\hline \multirow{2}{*}{ Domain } & \multirow{2}{*}{ Defect type } & No. of & \multicolumn{3}{c}{ Simulated $\mathbf{P}_{\mathbf{3 2}}\left(\mathrm{m}^{2} / \mathrm{m}^{3}\right)$} \\
& & DFNs & Minimum & Maximum & Mean \\
\hline 1 & Joints & 5 & 0.24 & 0.28 & 0.26 \\
\hline 2 & Faults and shears & 500 & 0.02 & 0.23 & 0.09 \\
\hline 3 & Faults and shears & 100 & 0.08 & 0.33 & 0.15 \\
\hline 4 & Faults and shears & 5 & 0.05 & 0.1 & 0.07 \\
\hline
\end{tabular}

\section{$5 \quad$ Stability analyses}

\subsection{Introduction}

Following validation of five representative fracture networks for each structural domain, a large number of networks were generated for stochastic stability analyses. These analyses focused on Domains 2 and 3 , which are discussed here. For Domain 2, 500 DFNs were produced (125 for each of the four slope aspects analysed), while Domain 3 had 100 DFNs produced (50 for each of the two slope aspects analysed).

The rock wedge module of the FracMan ${ }^{\circledR}$ software was used to simulate block stability for a representative pit surface. Both stable and unstable blocks are found by the rock wedge analysis. However, it is important to note that the program will only find blocks that are perfectly formed by fractures. It also only considers block faces that intersect the slope face (free face) when evaluating possible sliding faces and reports the maximum Factor of Safety (FS) from all possible sliding faces.

The FS for a block is calculated in different ways, depending on the failure mode of a given block. Stable blocks, which are unconditionally stable and effectively have an infinite FS are allocated a FS = 100 by the software, while free falling blocks have a $F S=0$. Between these two end members lies sliding on one or two planes. The FS for these two failure modes, in this study, is calculated using the Mohr-Coulomb model with the specific formulas provided by Dershowitz et al. (2011).

It should be noted that the rock block calculations are based on a stochastic fracture model, thus the derived block locations cannot be considered as real block positions. Instead, the analysis provides an indication of the number and size of the blocks that may be expected for a particular slope aspect, which must be related back to the actual length of the pit slope.

\subsection{Inputs}

Representative pit slope geometry was built as a surface in the three-dimensional modelling software Vulcan and then imported into the DFN software. For each domain the analysed slope height was consistently $480 \mathrm{~m}$, with $30 \mathrm{~m}$ high benches. The pit slope parameters specific to each domain are summarised in Table 2. 
Table 2 Analysed pit slope geometry

\begin{tabular}{ccccccc}
\hline Domain & Slope aspect & $\begin{array}{c}\text { Inter-ramp } \\
\text { angle }\left(^{\circ}\right)\end{array}$ & $\begin{array}{c}\text { Bench face } \\
\text { angle }\left({ }^{\circ}\right)\end{array}$ & $\begin{array}{c}\text { Bench } \\
\text { height }(\mathbf{m})\end{array}$ & $\begin{array}{c}\text { Overall slope } \\
\text { height }(\mathbf{m})\end{array}$ & $\begin{array}{c}\text { Analysed slope } \\
\text { length }(\mathbf{m})\end{array}$ \\
\hline 2 & 140 & & & & & \\
& 180 & 51 & 75 & 30 & & \\
& 225 & & & & & \\
3 & 315 & & & & & \\
\hline
\end{tabular}

A density of $3.5 \mathrm{t} / \mathrm{m}^{3}$ was applied for the Crystalline Basement with no water pressure assumed. Mohr-Coulomb defect shear strengths were based on laboratory testing, these being a cohesion of $0 \mathrm{kPa}$ and a friction angle of $20^{\circ}$.

\subsection{Rock block results}

Attributes calculated by the software for each block include volume, mass and a FS based on a stability analysis. An in-house script was developed to calculate the surface area of the block faces that intersect the slope, which allowed estimation of the percentage area of pit face affected by unstable blocks.

The results from the rock block analysis are summarised in Table 3 and an example output from a single model provided in Figure 9. The results of the analysis were considered both in terms of number of blocks failed and in the area of pit face failed. Graphs of mean and maximum unstable block volumes and area of pit slope were produced separately for each domain and slope aspect. Example results for two slope aspects from Domain 2 are provided in Figure 10.

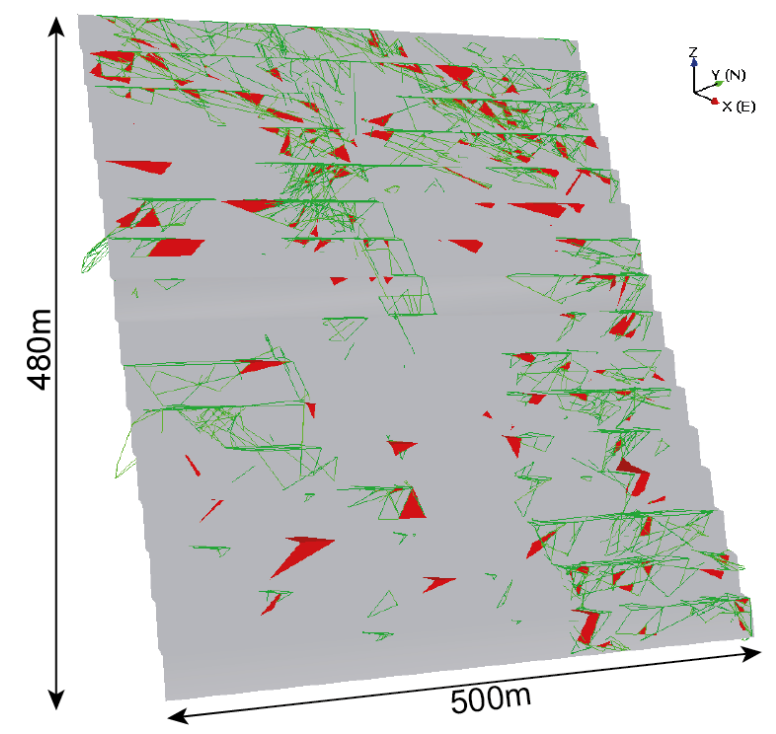

Figure 9 An example of blocks identified by the rock block analysis for Domain 3. Unstable blocks $(\mathrm{FS}<1)$ are solid, stable blocks (FS $>1)$ are wireframes

The analyses indicate that the area of slope failure is less than $4.5 \%$ and the failures are small. This suggests that the extent of liberated blocks are in accord with the selected design criteria (less than $5 \%$ chance of failure) and are in agreement with the traditional statistical assessment of the structural data. The results also highlight the influence of slope aspect, with $140^{\circ}$ (Domain 2) and $120^{\circ}$ (Domain 3) showing significantly higher numbers of failed blocks and area of pit face failed compared with other slope aspects. 

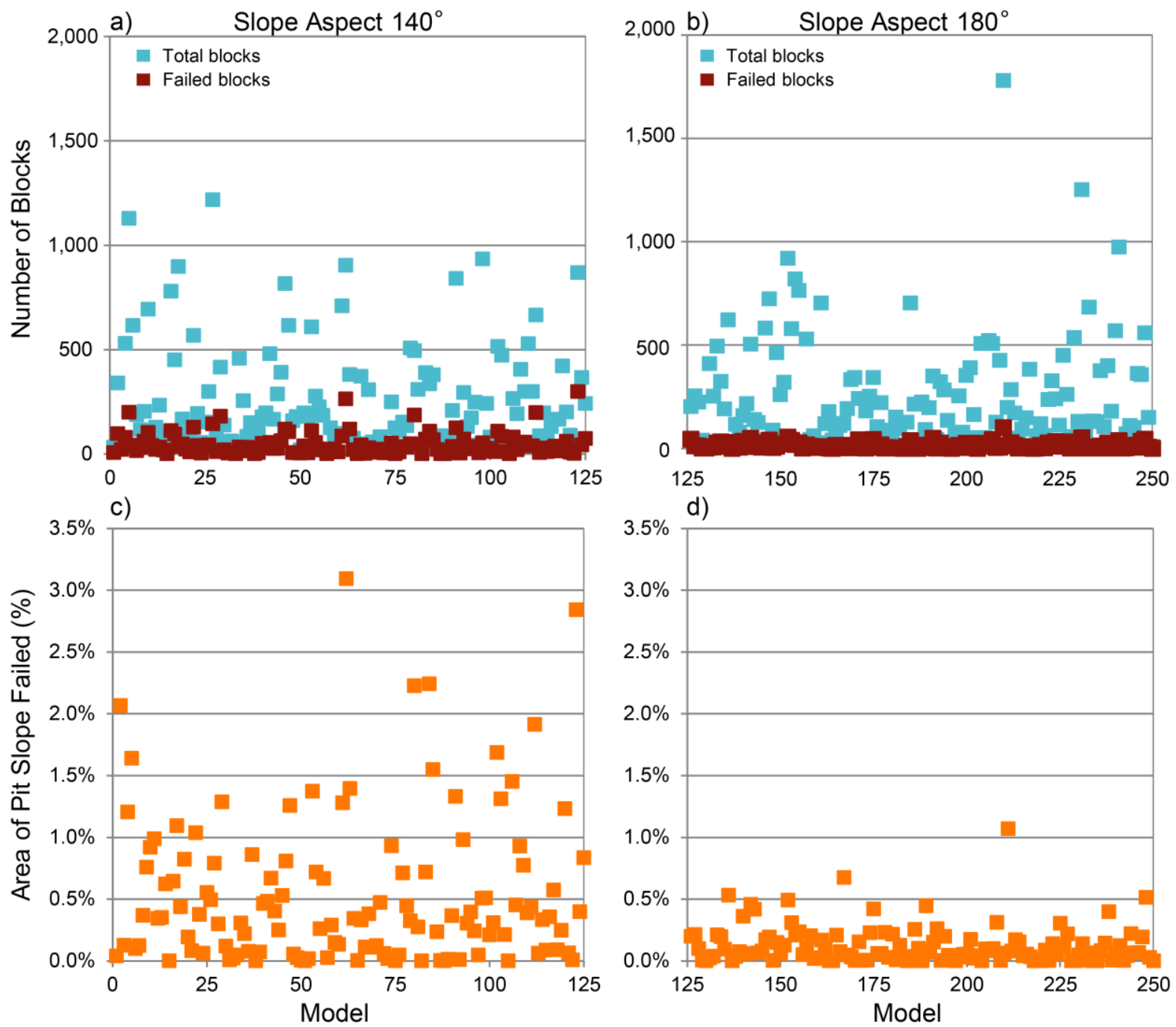

Figure 10 Results from Domain 2 rock block analysis for slope aspects 140 and 180 in terms of: (a) and (b) number of blocks for each model; and, (c) and (d) area of pit slope failed

Table 3 Results for block analysis

\begin{tabular}{ccccccc}
\hline \multirow{2}{*}{ Domain } & $\begin{array}{c}\text { Slope } \\
\text { aspect }\end{array}$ & \multicolumn{2}{c}{ Number of failed blocks } & \multicolumn{3}{c}{ Area of pit face failed (\%) } \\
\cline { 2 - 7 } & Minimum & Maximum & Minimum & Maximum & Mean \\
\hline \multirow{2}{*}{2} & 140 & 0 & 298 & 0 & 3.1 & 0.5 \\
& 180 & 0 & 43 & 0 & 1.1 & 0.1 \\
& 225 & 0 & 114 & 0 & 1.2 & 0.1 \\
& 315 & 0 & 122 & 0 & 0.8 & 0.1 \\
3 & 125 & 0 & 771 & 0 & 4.5 & 0.4 \\
& 280 & 0 & 117 & 0 & 0.9 & 0.2 \\
\hline
\end{tabular}

The low number of unstable blocks (and thus areas of pit slope that failed) could partly be a function of the analysis methodology, which requires blocks to be defined by fully intersecting structures. Imperfectly bound blocks (i.e. where there is a small intact rock bridge), can prevent a block from being recognised and hence not considered by the rock wedge module. 
The intact portions of failures can be modelled in software programs such as FLAC3D or PFC where both rock mass and defects are modelled together. This approach lends itself to investigating simple to complex rock mass structural relationships and providing a detailed assessment of stability for a single or a small number of cases. The computational times involved in this type of modelling does not lend itself towards a probabilistic approach. In this study, the objective was stochastic stability analyses and so this type of analysis was not undertaken.

\section{Conclusion}

This paper presented DFN modelling and its application for the design of a large open pit in Australia. This paper discussed the data inputs, model development and validation for stochastic fracture network modelling of four structural domains.

A novel aspect of the case study site is the comprehensive three-dimensional faults model from the underground mine. This wireframe model has been used to provide calibration to the important, but otherwise theoretically derived, fracture density property $P_{32}$.

The fracture networks presented here were utilised in stochastic stability analyses to give a range of possible models, which indicate the real large-scale slope performance and stability.

The slope design acceptance criteria adopted, for analysis of structural data for inter-ramp slope angles, was 3 to $5 \%$ chance of failure. This criterion is in accord with industry best practice. The rock block stability analyses indicated the area of slope failure is less than $5 \%$, which is in accord with this criteria.

Potential future works for fracture network modelling at the site include consideration of fracture terminations.

\section{Acknowledgement}

The authors would like to thank Andrew de Ambrosis and Gareth Swarbrick for assistance in the development of the DFN modelling tools, process and understanding at PSM.

\section{References}

Barton, C \& La Pointe, P 1995, Fractals in the Earth Sciences, Plenum Press, New York, p. 265.

Coates, DF 1981, Rock Mechanics Principles, Energy, Mines and Resources Canada, Monograph, p. 874.

Dershowitz, WS, Lee, G, Geier, J, Foxford, T, La Pointe, P \& Thomas, A 2011, FracMan - Interactive Discrete Feature Data Analysis, Geometric Modelling and Exploration Simulations: User Documenation, version 7.4, Golder Associates, Seattle.

Gasc-Barbier, M, Ballion, A \& Virely, D 2008, 'Design of large cuttings in jointed rock', Bulletin of Engineering Geology and the Environment, vol. 67, pp. 227-235.

Geier, JE \& Thomas, AL 1996, Discrete-feature Modelling of the Aspo site: Discrete Fracture Network Models for the Repository Scale, Report 96:5, Swedish Nuclear Power Inspectorate, Stockholm.

Grenon, M \& Hadjigeorgiou, J 2008, 'A design methodology for rock slopes susceptible to wedge failure using fracture system modelling', Engineering Geology, vol. 96, pp. 78-93.

Mauldon, M \& Dershowitz, WS 2000, 'A multi-dimensional system of fracture abundance', Geological Society of America Annual Meeting: Abstracts with Programs, Nevada, 32(7).

Priest, SD 1993, Discontinuity Analysis for Rock Engineering, Chapman and Hall, London.

Rogers, S, Moffitt, K \& Chance, A 2006, 'Using realistic fracture network models for modelling block stability and groundwater flow in rock slopes', in Canadian Geotechnical Conference, Vancouver, pp. 1452-1459.

Starzec, P \& Andersson, J 2002, 'Probabalisitic predictions regarding key blocks using stochastic discrete fracture networks - examples from a rock cavern in south-east Sweden', Bulletin of Engineering Geology and the Environment, vol. 61, pp. 363-378.

Terzaghi, RD 1965, 'Sources of error in joint surveys', Geotechnique, vol. 15, pp. 287-304.

Weir, FM \& Fowler, M 2014, 'An introduction to discrete fracture network modelling and its geotechnical applications', in AusRock 2014: Third Australiasian Ground Control in Mining Conference, Sydney.

Weir, FM, de Ambrosis, A \& Fowler, M 2014, 'Discrete fracture network modelling for tunnel design in the Sydney Basin', in Proceedings of the 15th Australasian Tunnelling Conference 2014, Sydney, pp. 219-228. 